\title{
Surgical site complications in kidney transplant recipients: incidence, risk factors and outcomes in the modern era
}

\author{
Rebecca Bic Kay Wong, BSc \\ Michelle Minkovich, BSc \\ Olusegun Famure, MPH, MEd \\ Yanhong Li, MSc \\ Jason Young Lee, MD, MHPE \\ Markus Selzner, MD \\ S. Joseph Kim, MD, PhD \\ Anand Ghanekar, MD, PhD
}

Presented as a poster at the 2019 American Transplant Congress, June 1-5, 2019, Boston, Mass.

Accepted Jan. 12, 2021

\author{
Correspondence to: \\ A. Ghanekar \\ Toronto General Hospital \\ University Health Network \\ 9-MaRS-9050, 585 University Ave \\ Toronto ON M5G 2N2 \\ Anand.Ghanekar@uhn.ca
}

Cite as: Can J Surg 2021 December 21; 64(6). doi: 10.1503/cjs.015820
Background: Surgical site complications (SSCs) are an important source of morbidity after kidney transplantation. We assessed the incidence, risk factors, outcomes and economic impact of SSCs in a large, diverse population of kidney transplant recipients.

Methods: We conducted a single-centre, observational cohort study of adult (age $\geq 18 \mathrm{yr}$ ) patients who underwent kidney transplantation between Jan. 1, 2005, and Dec. 31, 2015, with a minimum of 1 year of follow-up. Cases of SSC, including infections and wound dehiscence, were determined from patient records. Inpatient and outpatient hospital costs were determined 6 and 12 months after transplantation. We used the Kaplan-Meier product-limit method to determine the cumulative probability of SSCs and other outcomes. We evaluated risk factors and clinical outcomes using Cox proportional hazard ratios. Linear regression models were used to study the effect of SSCs on graft function.

Results: The incidence rate of SSCs within 30 days after transplantation was 4.19 per 100 person-months. The cumulative probability of developing an SSC within 30 days after transplantation was $4.13 \%$ (95\% confidence interval [CI] 3.23\%-5.28\%). Increased recipient body mass index (BMI) (hazard ratio [HR] 1.07, 95\% CI 1.021.11), longer cold ischemic time (HR 1.05, 95\% CI 1.01-1.09) and transplantation in 2010-2012 versus 2005-2009 (HR 2.20, 95\% CI 1.19-4.04) were risk factors for SSC development. In multivariable stepwise Cox proportional hazard models, SSC was a significant risk factor for death-censored graft failure (HR 3.08, 95\% CI 1.60-5.90) and total graft failure (HR 2.09, 95\% CI 1.32-3.32). Cumulative median hospital costs were \$2238.46 greater for patients with an SSC than for those without.

Conclusion: Increased BMI, longer cold ischemic time and the 2010-2012 transplantation period predisposed to SSCs. The development of SSCs was associated with a higher risk of graft failure. Strategies to minimize SSCs may improve outcomes after kidney transplantation and reduce costs.

Contexte : Les complications affectant le site opératoire (CSO) sont une importante cause de morbidité après la transplantation rénale. Nous avons évalué l'incidence, les facteurs de risque, les résultats et l'impact économique des CSO auprès d'une volumineuse population hétérogène de receveurs de transplantations rénales.

Méthodes : Nous avons procédé à une étude de cohorte d'observation monocentrique regroupant des patients adultes (âge $\geq 18$ ans) soumis à une transplantation rénale entre le $1^{\text {er }}$ janvier 2005 et le 31 décembre 2015, et suivis pendant au moins 1 an. Les cas de CSO, incluant les infections et les déhiscences de plaies ont été confirmés à partir des dossiers des patients. Le coût des hospitalisations et des soins ambulatoires a été calculé 6 et 12 mois après la transplantation. Nous avons utilisé l'estimateur de produit-limite de Kaplan-Meier pour établir la probabilité cumulative de CSO et d'autres paramètres. Nous avons évalué les facteurs de risque et les paramètres cliniques par la méthode des risques proportionnels de Cox. Des modèles de régression linéaire ont servi à l'analyse de l'impact des CSO sur le fonctionnement des greffons.

Résultats : Le taux d'incidence des CSO dans les 30 jours suivant la transplantation a été de 4,19 par 100 mois-personnes. La probabilité cumulative d'une CSO dans les 30 jours suivant la transplantation a été de 4,13\% (intervalle de confiance [IC] de $95 \% 3,23 \%-5,28 \%)$. Les facteurs de risque de CSO étaient indice de masse corporelle (IMC) élevé (risque relatif [RR] 1,07, IC de $95 \%$ 1,02-1,11), durée plus longue de l'ischémie froide (RR 1,05, IC de $95 \%$ 1,01-1,09) et transplantation effectuée en 2010-2012 c. 2005-2009 (RR 2,20, IC de 95\% 1,19-4,04). Dans les modèles à risques 


\begin{abstract}
proportionnels de Cox multivariés séquentiels, les CSO ont été d'importants facteurs de risque d'échec du greffon après censure des décès survenus avec des greffons fonctionnels (RR 3,08, IC de $95 \%$ 1,60-5,90) et d'échec total du greffon (RR 2,09, IC de $95 \% 1,32-3,32)$. Les coûts hospitaliers médians cumulatifs ont été de 2238,46 \$ de plus chez les patients ayant connu une CSO par rapport aux patients indemnes de CSO.
\end{abstract}

Conclusion : Un IMC élevé, une durée plus longue de l'ischémie froide et la transplantation effectuée entre 2010 et 2012 ont prédisposé les patients à des CSO. Les CSO ont été associées à un risque plus grand d'échec du greffon. Les stratégies visant à prévenir les CSO pourraient améliorer les résultats de la transplantation rénale et en réduire les coûts.

K idney transplantation is the preferred treatment for end-stage renal disease, offering enhanced survival and quality of life as compared to dialysis. However, surgical site complications (SSCs) represent an important source of morbidity for kidney transplant recipients. Several factors may contribute to the development of SSCs, including the recipient's body mass index (BMI) or history of diabetes, the quality of the donor organ, unsterile practices and posttransplantation immunosuppressive therapy. ${ }^{1-5}$ Previous investigators reported the incidence of SSCs, including surgical site infections (SSIs) and wound dehiscence, in kidney transplant recipients to range from $2 \%$ to $26 \% ;, ;$ however, these studies were published in 2012 and 2007, and SSI and wound dehiscence were considered separately. Surgical site complications typically arise early in the posttransplantation period and may affect short- to intermediate-term outcomes of the patient. ${ }^{8}$ Clinical outcomes reported to be associated with SSC include hospital readmission, delayed graft function, graft loss and death. ${ }^{1,9,10}$ Furthermore, SSCs are associated with a substantial economic impact on both hospitals and patients. ${ }^{11,12}$

Despite efforts to minimize SSCs through improved surgical techniques, perioperative antibiotic prophylaxis, targeted therapy and optimized immunosuppression, they remain a major clinical challenge. ${ }^{13-15}$ Recent trends toward the increased use of marginal kidney donors in combination with transplantation in patients with a greater burden of comorbidities, including diabetes, older age and higher BMI, may be contributing factors. ${ }^{16-18}$ A more precise understanding of the factors associated with the development of SSCs in the modern era, and the burden of SSCs on patients and health care providers, would allow for targeted quality-improvement initiatives.

In this study, we assessed SSCs at a high-volume Canadian transplantation centre by measuring the incidence of SSCs in kidney transplant recipients, identifying risk factors, studying their association with early and intermediate-term clinical outcomes, and quantifying their economic impact. Although a variety of surgical complications may arise after transplantation, this study focuses primarily on complications related to the surgical incision itself.

\section{Methods}

\section{Study design and population}

This single-centre cohort study used existing data for adult (age $\geq 18 \mathrm{yr}$ ) patients who underwent kidney transplantation between Jan. 1, 2005, and Dec. 31, 2015, with a minimum of 1 year of follow-up. Patients were excluded if they had received a prior nonkidney transplant or a simultaneous multiorgan transplant, or underwent transplantation at an outside centre.

\section{Data sources}

Data for this study regarding the type and severity of SSC (defined as wound dehiscence or an SSI) were collected from patient medical records accessed through our institution's organ transplantation tracking record and electronic patient record. We obtained data such as patient demographic characteristics, median household income, donor information and information about the transplantation procedure from the institution's Comprehensive Renal Transplant Research Information System, a database that houses pre-, peri- and posttransplantation information concerning kidney transplant recipients. ${ }^{19} \mathrm{We}$ obtained inpatient- and outpatient-related hospital cost data from the institutional finance department. The study was approved by the University Health Network Research Ethics Board.

\section{Selection of cases}

We examined patient records to determine SSC cases as classified by the International Statistical Classification of Diseases and Related Health Problems, Tenth Revision. ${ }^{20}$ Surgical site complications comprise wound dehiscence and SSIs, defined to include abscesses and infected fluid collections. We defined and grouped superficial, deep and organ/space infection using the criteria set forth by the U.S. Centers for Disease Control and Prevention, which capture SSC cases within 30 days of the transplantation. ${ }^{21}$ We defined wound dehiscence as the spontaneous opening of the skin and subcutaneous tissues of a surgical wound within 30 days after transplantation. Ambiguous cases were adjudicated by experts in the field. 


\section{Covariates}

Recipient, donor and transplantation factors were included in the risk factors and outcomes analyses, as they have the potential to affect the likelihood of an SCC and associated outcomes. Recipient factors included age at transplantation, sex, race, BMI, history of diabetes, history of cardiovascular disease, time spent receiving dialysis before transplantation, peak panel reactive antibody and median household income. Donor factors included age at donation, living versus deceased donor, and expanded-criteria donor (ECD) versus non-ECD. Transplantation factors included cold ischemic time, duration of surgery, delayed graft function, type of immunosuppression and transplantation period (2005-2009, 2010-2012 or 2013-2015). We defined transplantation period a priori based on sample sizes to allow for sufficient group sizes.

\section{Surgical site complications as exposure variable}

We analyzed the development of an SSC as a risk factor for posttransplantation outcomes including death-censored graft failure, death with graft function, total graft failure, kidney function and hospital readmission. Death-censored graft failure is defined as the return to long-term dialysis after transplantation. Total graft failure comprises a composite of death-censored graft failure and death with graft function. We calculated the estimated glomerular filtration rate 6 and 12 months after transplantation using the Chronic Kidney Disease Epidemiology Collaboration equation, which is the most widely used estimation of renal function in patients with native kidney disease and kidney transplant recipients. ${ }^{22}$

\section{Costs}

We determined the inpatient and outpatient hospital costs 6 and 12 months after transplantation to study the economic impact of the clinical management of SSCs. These costs included all costs incurred by the hospital during inpatient and outpatient care, such as for procedures, room and board, and laboratory tests, but did not include physician costs.

\section{Statistical analysis}

We used descriptive statistics to summarize recipient, donor and transplantation baseline characteristics. We used mean and median values to summarize normally distributed and skewed continuous risk factors, respectively. We obtained $p$ values from Student $t$ tests and Wilcoxon rank-sum tests. The distribution of categoric risk factors is presented as percentages. We calculated the cumulative probability of an SSC within 30 days after transplantation using the Kaplan-Meier product limit method and reported the incidence as a person-time incidence rate. Missing values were handled through multiple imputation, accounting for the uncertainties when predicting missing values, both within and between imputed data sets.

We identified risk factors for SSCs using univariable and multivariable Cox proportional hazards regression models to obtain hazard ratios (HRs) with $95 \%$ confidence intervals (CIs).

We evaluated the development of an SSC within 30 days after transplantation as a risk factor for the outcomes of death-censored graft failure, death with graft function and total graft failure using univariable and multivariable Cox proportional hazards regression models. Since patients had to survive with a functioning graft to 30 days after transplantation, any patients who were lost to follow-up or experienced graft failure (including death) during this period were excluded from the analysis of longterm outcomes. In addition, patients who did not receive induction therapy were excluded from the analysis of outcomes since it is the standard of care at this centre, and such cases are considered outliers. We studied the effect of an SSC on kidney function using simple and mixed linear regression models. ${ }^{23} \mathrm{We}$ compared the mean and median hospital costs of patients with and without SSCs 6 and 12 months after transplantation.

All analyses were conducted with Stata/MP, version 12.0 (StataCorp). A 2 -tailed $p$ value of $<0.05$ was considered statistically significant.

\section{Results}

We identified 2054 patients who underwent kidney transplantation between Jan. 1, 2005, and Dec. 31, 2015, of whom 553 were excluded (because of prior nonkidney transplantation or simultaneous multiorgan transplantation in 362 cases, and because the patient underwent transplantation outside our centre in 191). Thus, our cohort consisted of 1501 kidney transplant recipients. The mean recipient age at the time of transplantation was 50.8 (standard deviation 13.4) years, and 905 recipients $(60.3 \%)$ were male (Table 1). The type of donor was evenly divided, with 731 (48.7\%) being living donors and 770 (51.3\%) being deceased donors. The median duration of surgery was 2.3 (interquartile range [IQR] 2.0-2.7) hours.

There were 61 SSC events within the first month after transplantation. The incidence rate per 100 personmonths of the first SSC within 30 days of transplantation was 4.19 (95\% CI 3.26-5.39) (Appendix 1, Table S1, available at canjsurg.ca). The cumulative probability of developing an SSC within 30 days after transplantation was $4.13 \%$ (95\% CI 3.23\%-5.28\%) (Figure 1). Patients with an SSC had a median length of stay of 12 (IQR 8-20) days, compared to 8 (IQR 7-12) days for patients without an SSC. Of the 61 patients who developed an SSC within the first 30 days after transplantation, 41 (67\%) had only 
Table 1. Recipient, donor and transplantation characteristics for the entire cohort and for those with and without a surgical site complication within $\mathbf{3 0}$ days after transplantation*

\begin{tabular}{|c|c|c|c|}
\hline \multirow[b]{2}{*}{ Variable } & \multicolumn{3}{|c|}{ No. (\%) of patientst } \\
\hline & $\begin{array}{c}\text { Overall } \\
n=1501\end{array}$ & $\begin{array}{c}\text { No surgical site } \\
\text { complication } \\
n=1406\end{array}$ & $\begin{array}{c}\text { Surgical site } \\
\text { complication } \\
n=59\end{array}$ \\
\hline Recipient age at transplantation, mean $\pm \mathrm{SD}, \mathrm{yr}$ & $50.8 \pm 13.4$ & $50.7 \pm 13.5$ & $55.1 \pm 11.7$ \\
\hline \multicolumn{4}{|l|}{ Recipient sex } \\
\hline Male & $905(60.3)$ & $845(60.1)$ & 44 (74.6) \\
\hline Female & 596 (39.7) & $561(39.9)$ & $15(25.4)$ \\
\hline \multicolumn{4}{|l|}{ Recipient race } \\
\hline Nonwhite & - & 482 (34.3) & $24(40.7)$ \\
\hline White & - & $820(58.3)$ & $31(52.5)$ \\
\hline Missing & - & $104(7.4)$ & $4(6.8)$ \\
\hline Recipient body mass index, mean \pm SD $(n=1448)$ & $27.0 \pm 5.5$ & $26.9 \pm 5.5$ & $29.7 \pm 6.3$ \\
\hline \multicolumn{4}{|l|}{ Recipient history of diabetes } \\
\hline No & 1049 (69.9) & $994(70.7)$ & $29(49.2)$ \\
\hline Yes & $451(30.0)$ & $411(29.2)$ & $30(50.8)$ \\
\hline Missing & $1(0.1)$ & $1(0.1)$ & $0(0.0)$ \\
\hline \multicolumn{4}{|l|}{ Recipient history of cardiovascular disease } \\
\hline No & $1091(72.7)$ & $1028(73.1)$ & $38(64.4)$ \\
\hline Yes & $409(27.2)$ & $377(26.8)$ & $21(35.6)$ \\
\hline Missing & $1(0.1)$ & $1(0.1)$ & $0(0.0)$ \\
\hline Median time receiving dialysis (IQR), yr & $3.2(1.2-5.8)$ & $3.2(1.2-5.8)$ & $3.6(2.3-5.5)$ \\
\hline Median length of stay (IQR), $\mathrm{d}(n=1465)$ & $9(7-12)$ & $8(7-12)$ & $12(8-20)$ \\
\hline \multicolumn{4}{|l|}{ Peak panel reactive antibody, \% } \\
\hline 0 & - & $660(46.9)$ & $21(35.6)$ \\
\hline$>0$ & - & $745(53.0)$ & $38(64.4)$ \\
\hline Missing & - & $1(0.1)$ & $0(0.0)$ \\
\hline Donor age, mean \pm SD, yr $(n=1499)$ & $47.2 \pm 14.4$ & $47.0 \pm 14.3$ & $52.5 \pm 14.2$ \\
\hline \multicolumn{4}{|l|}{ Donor sex } \\
\hline Male & - & 701 (49.9) & 37 (62.7) \\
\hline Female & - & $699(49.7)$ & $22(37.3)$ \\
\hline Missing & - & $6(0.4)$ & $0(0.0)$ \\
\hline \multicolumn{4}{|l|}{ Donor type } \\
\hline Living & $731(48.7)$ & $687(48.9)$ & 21 (35.6) \\
\hline Deceased, ECD & $256(17.1)$ & $233(16.6)$ & 20 (33.9) \\
\hline Deceased, non-ECD & $514(34.2)$ & 486 (34.6) & 18 (30.5) \\
\hline \multicolumn{4}{|l|}{ Induction therapy } \\
\hline Nondepleting agent & - & $361(25.7)$ & $5(8.5)$ \\
\hline Depleting agent & - & $1045(74.3)$ & 54 (91.5) \\
\hline \multicolumn{4}{|l|}{ Calcineurin inhibitor type at discharge } \\
\hline Tacrolimus & - & 1209 (86.0) & 55 (93.2) \\
\hline Cyclosporine & - & $176(12.5)$ & $2(3.4)$ \\
\hline Missing & - & $21(1.5)$ & $2(3.4)$ \\
\hline Cold ischemic time, mean $\pm \mathrm{SD}, \mathrm{h}(n=712) \ddagger$ & $11.9 \pm 5.2$ & $11.8 \pm 5.1$ & $13.2 \pm 6.5$ \\
\hline Delayed graft function & - & $280(19.9)$ & $21(35.6)$ \\
\hline Median duration of surgery (IQR), $\mathrm{h}(n=1491)$ & $2.3(2.0-2.7)$ & - & - \\
\hline Median household income (IQR), $\$(n=1312)$ & $\begin{array}{c}66412 \\
(49053-88996)\end{array}$ & $\begin{array}{c}66358 \\
\text { (49 187-88 935) }\end{array}$ & $\begin{array}{c}70853 \\
(44058-93153)\end{array}$ \\
\hline \multicolumn{4}{|l|}{ Transplantation period } \\
\hline 2005-2009 & $630(42.0)$ & $589(41.9)$ & $17(28.8)$ \\
\hline 2010-2012 & $434(28.9)$ & $402(28.6)$ & $26(44.1)$ \\
\hline 2013-2015 & $437(29.1)$ & 415 (29.5) & $16(27.1)$ \\
\hline \multicolumn{4}{|c|}{$\begin{array}{l}\text { ECD = expanded-criteria donor; } I Q R=\text { interquartile range; } S D=\text { standard deviation. } \\
\text { *Thirty-six patients were excluded from the cohort since they were lost to follow-up or experienced graft failure during the first } 30 \text { days after } \\
\text { transplantation, or did not receive induction immunosuppression. } \\
\text { tExcept where noted otherwise. } \\
\text { fDeceased donors only. }\end{array}$} \\
\hline
\end{tabular}




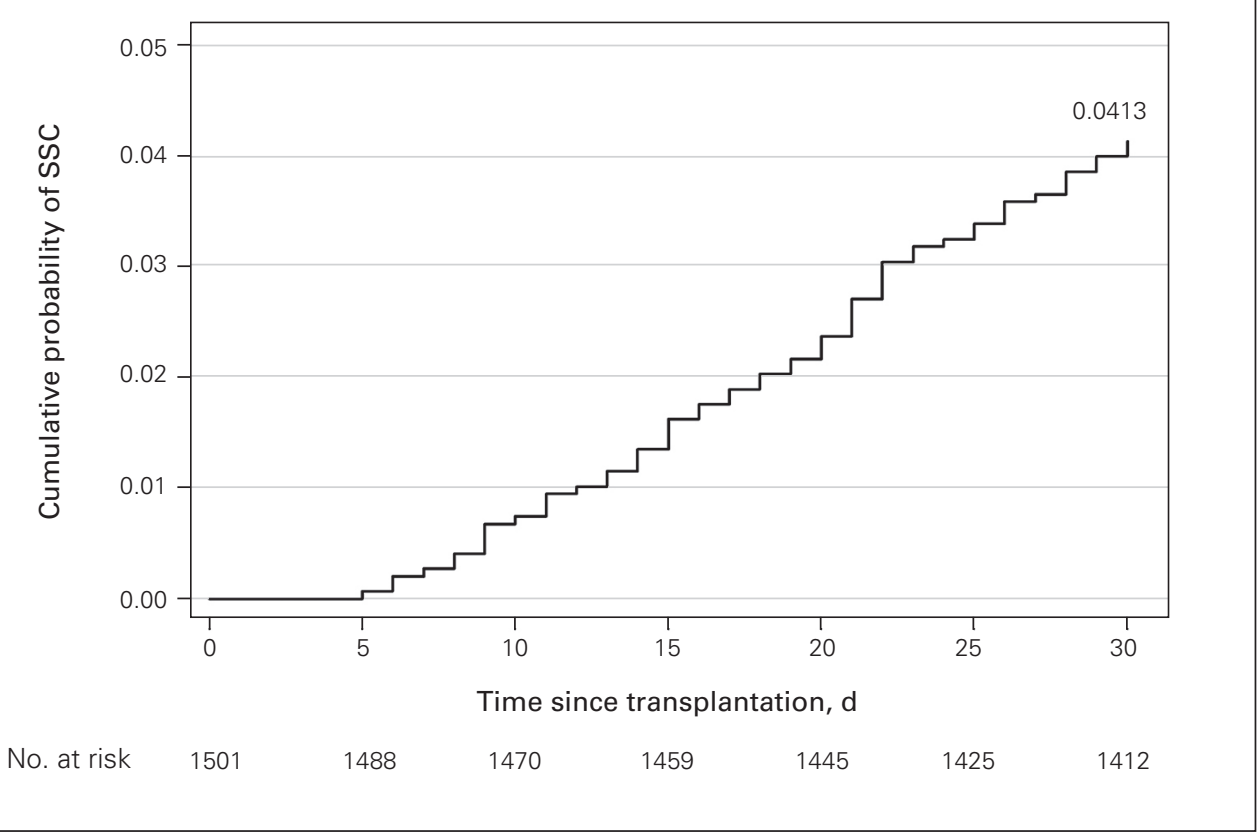

Fig. 1. Cumulative probability of the development of a surgical site complication (SSC) within the first 30 days after kidney transplantation.

Table 2. Univariable Cox proportional hazards model for risk factors for development of surgical site complications

\begin{tabular}{|lc|}
\hline Risk factor & HR (95\% Cl) \\
\hline Recipient age at transplantation (per 1-yr increase) & $1.03(1.01-1.05)$ \\
\hline Recipient sex (female v. male) & $0.53(0.30-0.95)$ \\
\hline Recipient body mass indexs (per 1 kg/m² increase) & $1.08(1.04-1.12)$ \\
\hline Recipient history of diabetes (yes v. no) & $2.32(1.40-3.83)$ \\
\hline $\begin{array}{l}\text { Recipient history of cardiovascular disease (yes } \\
\text { v. no) }\end{array}$ & $1.53(0.91-2.59)$ \\
\hline Time receiving dialysis (per 1-yr increase) & $1.04(0.96-1.11)$ \\
\hline Donor age (per 1-yr increase) & $1.03(1.01-1.05)$ \\
\hline Donor type & $2.78(1.51-5.13)$ \\
\hline Deceased ECD v. living & $1.35(0.73-2.48)$ \\
\hline$\quad$ Deceased non-ECD v. living & $1.06(1.02-1.09)$ \\
\hline Cold ischemic time (per 1-h increase) & $1.93(1.53-2.44)$ \\
\hline Duration of surgery (per 1-h increase) & $0.99(0.96-1.03)$ \\
\hline Median household income (per \$5000 increase) & $2.33(1.27-4.27)$ \\
\hline Transplantation period & $1.44(0.74-2.83)$ \\
\hline 2010-2012 v. 2005-2009 & \\
\hline 2013-2015 v. 2005-2009 & \\
\hline Cl = confidence interval; ECD = expanded-criteria donor; HR = hazard ratio. \\
\hline
\end{tabular}

wound dehiscence, 10 (16\%) had only SSI, and 10 (16\%) had both. Of the 51 patients who experienced wound dehiscence, only 2 (4\%) had dehiscence of the fascia.

Of the 20 patients with an SSI, 9 (45\%) had a superficial SSI, 4 (20\%) had a deep SSI, and 7 (35\%) had an organ/space SSI. Gram-negative bacteria were grown in SSI cultures from 12 patients (60\%), 6 (50\%) of whom had gram-positive bacteria, with the most common being
Pseudomonas aeruginosa (Appendix 1, Table S2). The most common type of gram-positive bacteria found was coagulase-negative Staphylococcus (4 cases [20\%]). Yeast was found in the surgical site of 1 patient (5\%), 3 patients $(15 \%)$ had only commensal flora, and 3 patients $(15 \%)$ had no culture done.

Most risk factors for SSCs were found to be significant in univariable analyses, such as recipient BMI (HR 1.08 per $1 \mathrm{~kg} / \mathrm{m}^{2}$ increase, 95\% CI 1.04-1.12), donor age (HR 1.03 per 1 -yr increase, $95 \%$ CI $1.01-1.05)$, cold ischemic time (HR 1.06 per 1 -h increase, 95\% CI $1.02-1.09$ ) and transplantation in 2010-2012 versus 2005-2009 (HR 2.33, $95 \%$ CI 1.27-4.27) (Table 2). Factors that were not associated with development of an SSC included recipient history of cardiovascular disease, time spent receiving dialysis, and deceased non-ECD compared to living donor.

On multivariable stepwise Cox proportional hazards analysis, 3 risk factors were found to be significantly associated with the development of SSCs: greater recipient BMI (HR 1.07 per $1 \mathrm{~kg} / \mathrm{m}^{2}$ increase, 95\% CI 1.02-1.11), longer cold ischemic time (HR 1.05 per 1-h increase, 95\% CI 1.01-1.09) and transplantation in 2010-2012 versus 20052009 (HR 2.20, 95\% CI 1.19-4.04) (Table 3). The degree of missingness of variables included in the models is provided in Appendix 1, Table S3.

For analysis of the clinical outcomes of death-censored graft failure, death with graft function, total graft failure and hospital readmission, 36 patients were excluded since they were lost to follow-up or experienced graft failure during the first 30 days after transplantation, or did not 
Table 3. Multivariable Cox stepwise model for risk factors for development of surgical site complications

\begin{tabular}{|lc|}
\hline Risk factor & HR (95\% Cl) \\
\hline Recipient age at transplantation (per 1-yr increase) & $1.01(0.99-1.03)$ \\
\hline Recipient body mass index (per 1 kg/m² increase) & $1.07(1.02-1.11)$ \\
\hline Donor age (per 1-yr increase) & $1.02(1.00-1.04)$ \\
\hline Cold ischemic time (per 1-h increase) & $1.05(1.01-1.09)$ \\
\hline Duration of surgery (per 1-h increase) & $1.60(0.94-2.73)$ \\
\hline Transplantation period & $2.20(1.19-4.04)$ \\
\hline 2010-2012 v. 2005-2009 & $1.30(0.66-2.57)$ \\
\hline 2013-2015 v. 2005-2009 \\
\hline $\mathrm{Cl}=$ confidence interval; HR = hazard ratio. \\
\hline
\end{tabular}

receive induction immunosuppression. Among the remaining 1465 patients, there were 113 cases of deathcensored graft failure and 156 cases of death with graft function, giving 269 total graft failure events over 7529.84 person-years of follow-up. The incidence rates per 100 person-years of total graft failure and hospital readmission were 3.57 and 14.11, respectively (Appendix 1, Table S1). Univariable Cox regression models showed SSC to be a significant risk factor for death-censored graft failure (HR 3.47, 95\% CI 1.86-6.48), death with graft function (HR 2.37, [95\% CI 1.25-4.51) and total graft failure (HR 2.84, 95\% CI 1.82-4.44) (Table 4; Appendix 1, Figure S1). In multivariable stepwise Cox proportional hazard models, SSC was a significant risk factor for deathcensored graft failure (HR 3.08, 95\% CI 1.60-5.90) and total graft failure (HR 2.09, 95\% CI 1.32-3.32) but not for death with graft function. Development of an SSC was not an independent risk factor for hospital readmission in any of the Cox models.
Simple linear models and linear mixed models showed no significant of SSCs on estimated glomerular filtration rate (Appendix 1, Table S4).

At both 6 and 12 months after transplantation, the cumulative mean and median hospital costs were greater for patients with SSCs than for those without SSCs (mean at $12 \mathrm{mo} \$ 12462.67$ v. $\$ 11770.16$, median at $12 \mathrm{mo}$ $\$ 7557.25$ v. \$4879.27) (Table 5).

\section{Discussion}

The incidence of first SSC within 30 days after transplantation at a high-volume Canadian centre was 4.19 per 100 person-months, and the cumulative probability of cases within 30 days was $4.13 \%$, with most cases being wound dehiscence alone. Although the majority of potential risk factors for the development of SSC that were analyzed were significant when evaluated separately, multivariable analysis yielded only 3 significant risk factors: increased recipient $\mathrm{BMI}$, longer cold ischemic time and the 2010-2012 transplantation period. Surprisingly, recipient age, donor type (living donor v. deceased ECD v. deceased non-ECD) and duration of surgery were not found to be significant risk factors for SSCs in the multivariable models. The univariable and multivariable models for the likelihood of hospital readmission after SSC were not significant, and similar trends were observed when assessing the association between SSC and graft function. Notably, occurrence of an SSC increased the risk of death-censored graft failure and total graft failure in both univariable and multivariable models. Cases of superficial wound dehiscence were more common than SSIs. The most common type of gram-negative

\begin{tabular}{|c|c|c|c|}
\hline \multirow[b]{2}{*}{ Outcome } & \multicolumn{3}{|c|}{$\mathrm{HR}(95 \% \mathrm{Cl})$} \\
\hline & Univariable & Multivariable & $\begin{array}{l}\text { Multivariable } \\
\text { (stepwise) }\end{array}$ \\
\hline Death-censored graft failure & $3.47(1.86-6.48)$ & $2.90(1.46-5.75)$ & $3.08(1.60-5.90)$ \\
\hline Death with graft function & $2.37(1.25-4.51)$ & $1.62(0.81-3.23)$ & $1.58(0.82-3.06)$ \\
\hline Total graft failure & $2.84(1.82-4.44)$ & $2.04(1.26-3.31)$ & $2.09(1.32-3.32)$ \\
\hline $\begin{array}{l}\text { First hospital admission within } \\
\text { first year after transplantation }\end{array}$ & $0.81(0.52-1.25)$ & $0.75(0.48-1.17)$ & $0.74(0.48-1.14)$ \\
\hline
\end{tabular}

Table 5. Cumulative mean and median hospital costs incurred by patients with or without surgical site complications within 30 days of transplantation, 6 and 12 months after transplantation

\begin{tabular}{|c|c|c|c|c|c|c|}
\hline \multirow[b]{2}{*}{ Time period } & \multicolumn{3}{|c|}{ Cumulative mean cost per patient, $\$$} & \multicolumn{3}{|c|}{ Cumulative median cost per patient, $\$$} \\
\hline & $\begin{array}{c}\text { No surgical site } \\
\text { complication }\end{array}$ & $\begin{array}{l}\text { Surgical site } \\
\text { complication }\end{array}$ & Difference & $\begin{array}{c}\text { No surgical site } \\
\text { complication }\end{array}$ & $\begin{array}{l}\text { Surgical site } \\
\text { complication }\end{array}$ & Difference \\
\hline Within 6 mo after transplantation & 8128.84 & 9669.32 & 1540.48 & 3460.50 & 5259.43 & 1798.93 \\
\hline Within 12 mo after transplantation & 11770.16 & 12462.67 & 692.51 & 4879.27 & 7557.25 & 2677.98 \\
\hline
\end{tabular}


and gram-positive bacteria found in SSIs was P. aeruginosa and coagulase-negative Staphylococcus, respectively.

Recipient BMI has also been identified as a risk factor for SSC development in other studies. ${ }^{1,10,24}$ Although patients with higher BMI have similar survival benefits of transplantation as patients with lower $\mathrm{BMI},{ }^{25}$ specific wound-management strategies such as additional layers of subcutaneous sutures during wound closure and closedincision negative-pressure wound management may need to be considered in this group of patients to reduce the occurrence of SSCs, which are associated with substantial morbidity. ${ }^{26,27}$

Prolonged cold ischemia time has been previously identified as a risk factor for incisional infections after kidney transplantation. ${ }^{1,28}$ Since cold ischemic time is also associated with other adverse events following kidney transplantation, such as delayed graft function, ${ }^{29}$ this observation provides further rationale to minimize cold ischemic time whenever possible.

Importantly, SSCs were associated with an increased risk of death-censored graft failure and total graft failure; death-censored graft failure is likely to be the driving effect. Although it is possible to speculate on patient, graft and postoperative factors that likely contribute to this relation, further research is necessary to determine the specific mechanism behind this effect. Nevertheless, this finding provides a strong rationale to minimize SSCs in this group of surgical patients.

In addition to adverse clinical implications for patients, SSCs have an impact on hospital-related costs. This is likely related to the longer hospital stays required by patients with SSCs, more frequent outpatient visits, and additional costs associated with wound management and antimicrobial therapy. As our study focused on hospitalrelated inpatient and outpatient costs only, the total cost of SSCs is likely much higher than what we report here, since patients with SSCs often require prolonged therapy after discharge, including specialized wound monitoring and dressing care, antimicrobial therapy and community nursing visits.

\section{Limitations}

Our study relied on the recording of complications in clinical notes and charts by health care providers, and there is inherent variation between practitioners. To mitigate the variation, we established strict definitions of cases a priori, and the few ambiguous cases were adjudicated by experts in the field. Only a small number of SSCs were found, which may have been due to variation in sensitivity of reporting. This may have resulted in underrepresentation of SSC cases, but multiple data sources were used throughout collection to address this possibility. Furthermore, although this study was conducted at a single centre and the findings may lack generalizability, our centre is the largest kidney transplantation program in Canada, with a very diverse patient population, including different racial and socioeconomic groups.

\section{Conclusion}

This study shows the relevance of SSCs to both short- and intermediate-term outcomes of kidney transplant recipients. Increased BMI, longer cold ischemic time and the 2010-2012 transplantation period predisposed to SSC development, and SSCs were associated with a higher risk of graft failure. The identification of risk factors for SSCs presents opportunities for quality-improvement initiatives to decrease the occurrence of these complications in those at increased risk. Strategies to minimize the development of SSCs may improve outcomes of kidney transplant recipient and reduce costs.

Acknowledgements: The authors thank the students of the MultiOrgan Transplant Student Research Training Program for their assistance in data collection. The authors also acknowledge Nikita Gupta for her guidance in data collection and Kateryna Maksyutynska for her assistance in manuscript revision.

Affiliations: From the Kidney Transplant Program, Toronto General Hospital, University Health Network, Toronto, Ont. (Wong, Minkovich, Famure, Li, Lee, Selzner, Kim, Ghanekar); the Division of Nephrology, University Health Network, Toronto, Ont. (Lee); the Department of Surgery, University of Toronto, Toronto, Ont. (Lee, Selzner, Ghanekar); the Division of General Surgery, University Health Network, Toronto, Ont. (Selzner, Ghanekar); and the Department of Medicine, University of Toronto, Toronto, Ont. (Kim).

Competing interests: None declared.

Contributors: S.J. Kim and A. Ghanekar jointly supervised the work. O. Famure, M. Selzner, J. Lee, A. Ghanekar and S.J. Kim designed the study. R. Wong and M. Minkovich acquired the data, which R. Wong, Y. Li and S.J. Kim analyzed. R. Wong, M. Minkovich, O. Famure, A. Ghanekar and S.J. Kim wrote the manuscript, which all authors critically revised. All authors gave final approval of the article to be published.

Content licence: This is an Open Access article distributed in accordance with the terms of the Creative Commons Attribution (CC BYNC-ND 4.0) licence, which permits use, distribution and reproduction in any medium, provided that the original publication is properly cited, the use is noncommercial (i.e., research or educational use), and no modifications or adaptations are made. See: https://creativecommons. org/licenses/by-nc-nd/4.0/.

Funding: None declared.

\section{References}

1. Wszola M, Kwiatkowski A, Ostaszcwska A, et al. Surgical site infections after kidney transplantation - Where do we stand now? Transplantation 2013;95:878-82.

2. Freire MP, Antonopoulos I, Piovesan A, et al. Amikacin prophylaxis and risk factors for surgical site infection after kidney transplantation. Transplantation 2015;99:521-7.

3. Global guidelines for the prevention of surgical site infection. Geneva: World Health Organization; 2018.

4. Knight RJ, Villa M, Laskey R, et al. Risk factors for impaired wound healing in sirolimus-treated renal transplant recipients. Clin Transplant 2007;21:460-5. 
5. Sandrini S, Setti G, Bossini N, et al. Steroid withdrawal five days after renal transplantation allows for the prevention of wound-healing complications associated with sirolimus therapy. Clin Transplant 2009;23:16-22.

6. Laftavi MR, Rostami R, Patel S, et al. Universal perioperative antimicrobial prophylaxis is not necessary in kidney transplantation. Clin Transplant 2012;26:437-42.

7. Sharma KK, Ayyagiri A, Dhole TN, et al. Prevalence of infections in renal transplant recipients of north India. Indian 7 Pathol Microbiol 2007;50:453-7.

8. Holihan JL, Flores-Gonzalez JR, Mo J, et al. How long is long enough to identify a surgical site infection? Surg Infect (Larcbmt) 2017;18:419-23.

9. Harhay M, Lin E, Pai A, et al. Early rehospitalization after kidney transplantation: assessing preventability and prognosis. Am 7 Transplant 2013;13:3164-72.

10. Lynch RJ, Ranney DN, Shijie C, et al. Obesity, surgical site infection, and outcome following renal transplantation. Ann Surg 2009; 250:1014-20.

11. Hollenbeak CS, Alfrey EJ, Souba WW. The effect of surgical site infections on outcomes and resource utilization after liver transplantation. Surgery 2001;130:388-95.

12. Ho D, Lynch RJ, Ranney DN, et al. Financial impact of surgical site infection after kidney transplantation: implications for quality improvement initiative design. 7 Am Coll Surg 2010;211:99-104.

13. Krajewski E, Soriano IS, Ortiz J. Laparoscopy in transplantation. 7SLS 2006;10:426-31.

14. Wagenaar S, Nederhoed JH, Hoksbergen AWJ, et al. Minimally invasive, laparoscopic, and robotic-assisted techniques versus open techniques for kidney transplant recipients: a systematic review. Eur Urol 2017;72:205-17.

15. Pratschke J, Dragun D, Hauser IA, et al. Immunological risk assessment: the key to individualized immunosuppression after kidney transplantation. Transplant Rev (Orlando) 2016;30:77-84.

16. Hwang JK, Park SC, Kwon KH, et al. Long-term outcomes of kidney transplantation from expanded criteria deceased donors at a single center: comparison with standard criteria deceased donors. Transplant Proc 2014;46:431-6.

17. Berger JC, Muzaale AD, James N, et al. Living kidney donors ages 70 and older: recipient and donor outcomes. Clin 7 Am Soc Nephrol 2011;6:2887-93.
18. Reese PP, Feldman HI, Asch DA, et al. Short-term outcomes for obese live kidney donors and their recipients. Transplantation 2009; 88:662-71.

19. Famure O, Phan NA, Kim SJ. Health information management for research and quality assurance: the Comprehensive Renal Transplant Research Information System. Healthc Manage Forum 2014;27:30-6.

20. International statistical classification of diseases and related health problems, tenth revision. Geneva: World Health Organization; 1992.

21. Horan TC, Gaynes RP, Martone WJ, et al. CDC definitions of nosocomial surgical site infections, 1992: a modification of CDC definitions of surgical wound infections. Infect Control Hosp Epidemiol 1992;13:606-8.

22. Levey AS, Stevens LA, Schmid CH, et al.; Chronic Kidney Disease Epidemiology Collaboration. A new equation to estimate glomerular filtration rate. Ann Intern Med 2009;150:604-12.

23. Leffondre K, Boucquemont J, Tripepi G, et al. Analysis of risk factors associated with renal function trajectory over time: a comparison of different statistical approaches. Nephrol Dial Transplant 2015;30: 1237-43.

24. Menezes FG, Wey SB, Peres CA, et al. What is the impact of surgical site infection on graft function in kidney transplant recipients? Transpl Infect Dis 2010;12:392-6.

25. Hill CJ, Courtney AE, Cardwell CR, et al. Recipient obesity and outcomes after kidney transplantation: a systematic review and metaanalysis. Nephrol Dial Transplant 2015;30:1403-11.

26. Røine E, Bjørk IT, Oyen O. Targeting risk factors for impaired wound healing and wound complications after kidney transplantation. Transplant Proc 2010;42:2542-6.

27. Norman G, Goh EL, Dumville JC, et al. Negative pressure wound therapy for surgical wounds healing by primary closure. Cocbrane Database Syst Rev 2020;(5):CD009261.

28. Moris D, Davakis S, Kakavia K, et al. Incisional infections after renal transplant: outcome data from 238 consecutive recipients. Exp Clin Transplant 2017;15:405-13.

29. Aceto P, Perilli V, Luca E, et al. Perioperative-, recipient-, and donor-related factors affecting delayed graft function in kidney transplantation. Exp Clin Transplant 2019;17:575-9. 